\title{
Benign polypi at the site of uretero-rectal anastomosis
}

\author{
Ambati S. Narayana \\ M.S., M.D., F.R.C.S.I.*
}

D. G. KeLLY

M.Ch., F.R.C.S.I. $\dagger$

\author{
F. A. DufF \\ M.Ch., F.R.C.S.I. $\dagger$ \\ *Department of Urology, University of Iowa Hospitals and Clinics, Iowa City, Iowa, and \\ $\dagger$ Department of Urology, St Vincent's Hospital, Dublin, Ireland
}

\section{Summary}

A case of benign polypi at the site of uretero-rectal anastomosis is herein reported. Nine other similar cases are reviewed. Possible aetiology and diagnosis are discussed.

\section{Introduction}

Even though ileal conduit, which was popularized by Bricker (1950), has largely replaced ureterosigmoidostomy, the latter is still used in some centres as a procedure of choice for urinary diversion.

Development of neoplasia at the site of anastomosis is rare. Hammer (1929) described the first case of carcinoma in a 60-year-old man 10 years after uretero-sigmoidostomy. Very few cases of benign polypi have been reported. There is no report of two polyps developing at the site of uretero-colonic anastomosis at the same time. Such a case is now reported.

\section{Case report}

A 22-year-old woman complaining of rectal bleeding was admitted to St Vincent's Hospital, Dublin. The patient had undergone uretero-rectal anastomosis for bladder exstrophy at 6 years of age. Her renal status on admission was good with a GFR by EDTA of $120 \mathrm{ml} / \mathrm{min}$. Rectal examination was negative except for blood on the examining finger.
Sigmoidoscopy showed two polypoidal masses at the site of uretero-rectal anastomosis. The ureteric openings were identified by injecting methylene blue. Both polypoidal growths were removed and the pedicles were secured with catgut sutures. The patient developed mild pain in the right loin on the first postoperative day. The pain became colicky in the next 2 days and the temperature rose to $101^{\circ} \mathrm{F}$. On examination, the right renal angle was tender. An intravenous pyelogram showed an obstructed right lower ureter. The next day a catgut suture obstructing the right ureteric orifice was removed following which the pain and temperature subsided. Follow-up intravenous pyelogram was normal and a barium enema showed a normal large bowel. Histologically the masses were found to be benign adenomatous polypi (Fig. 1).

\section{Discussion}

Only nine cases of benign tumours arising at the site of uretero-colonic anastomosis have previously been reported. These are detailed in Table 1. This patient is the tenth. The average age of the patients was 31.8 years. There are varied opinions about aetiological factors which are more speculative than definitive, but one common factor in all the cases is uretero-colonic anastomosis. Aldis (1961) suggested that the mechanical trauma to the pseudopolyp

TABLE 1. Benign adenomatous polyp complicating uretero-colonic anastomosis

\begin{tabular}{|c|c|c|c|}
\hline Reference & $\begin{array}{c}\text { Age (Sex) } \\
\text { (years) }\end{array}$ & Original condition & $\begin{array}{l}\text { Latency } \\
\text { (years) }\end{array}$ \\
\hline Ellis (1962) & $55(\mathrm{M})$ & Abacterial cystitis & 14 \\
\hline Gillman (1964) & $82(\mathrm{M})$ & Vesical papilloma & 7 \\
\hline Markowitz and Koontz (1966) & $16(F)$ & Exstrophy & 14 \\
\hline Markowitz and Koontz (1966) & $16(\mathrm{M})$ & Exstrophy & 15 \\
\hline Markowitz and Koontz (1966) & $19(\mathrm{M})$ & Exstrophy & 18 \\
\hline Ferguson (1966) & $30(\mathrm{M})$ & Exstrophy & 26 \\
\hline Kille and Glick (1967) & 19 (M) & Epispadias & 15 \\
\hline MacGregor (1968) & $62(\mathrm{M})$ & Transitional cell carcinoma of bladder & 5 \\
\hline Haney and McGarity (1971) & $44(F)$ & Exstrophy & 38 \\
\hline Present case & $22(\mathrm{~F})$ & Exstrophy & 16 \\
\hline
\end{tabular}




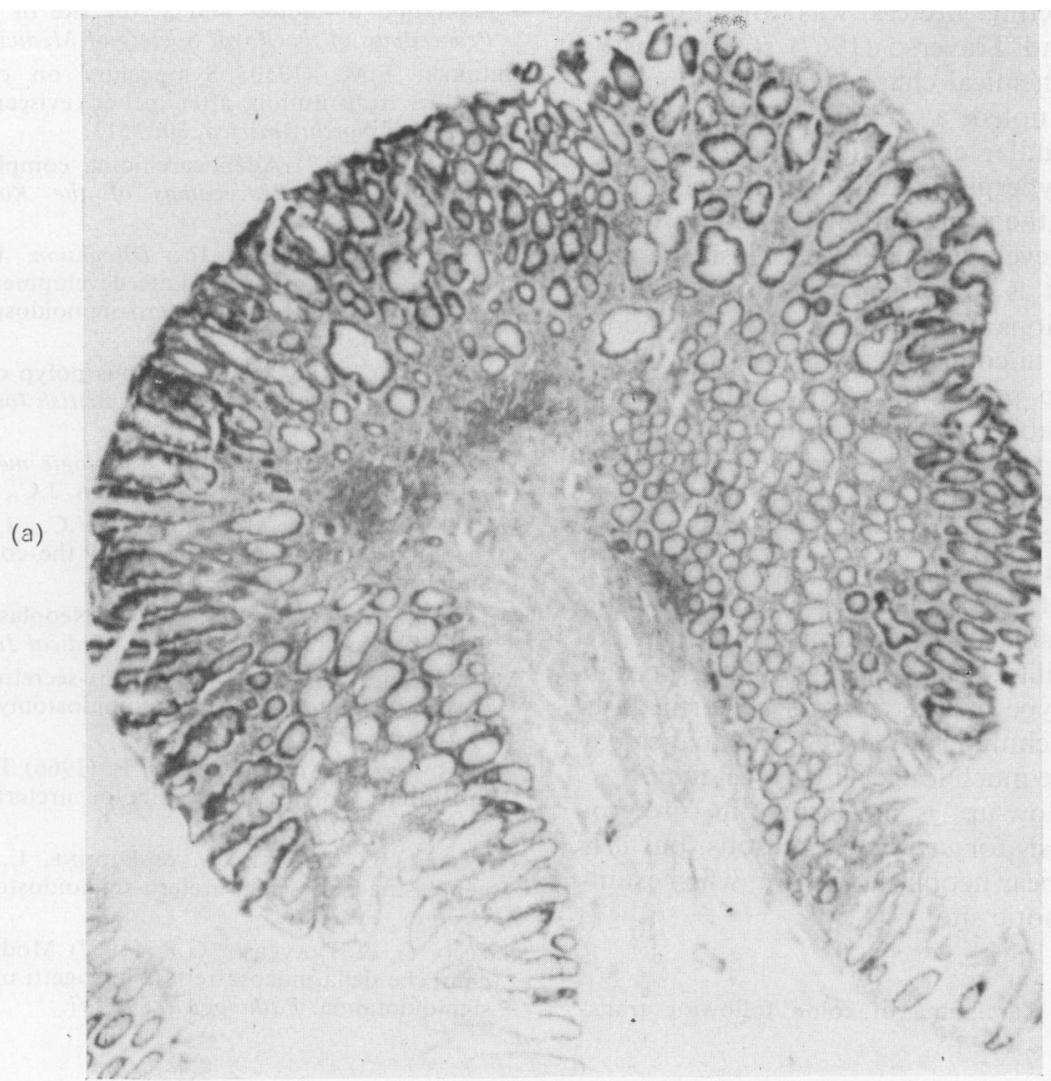

(b)

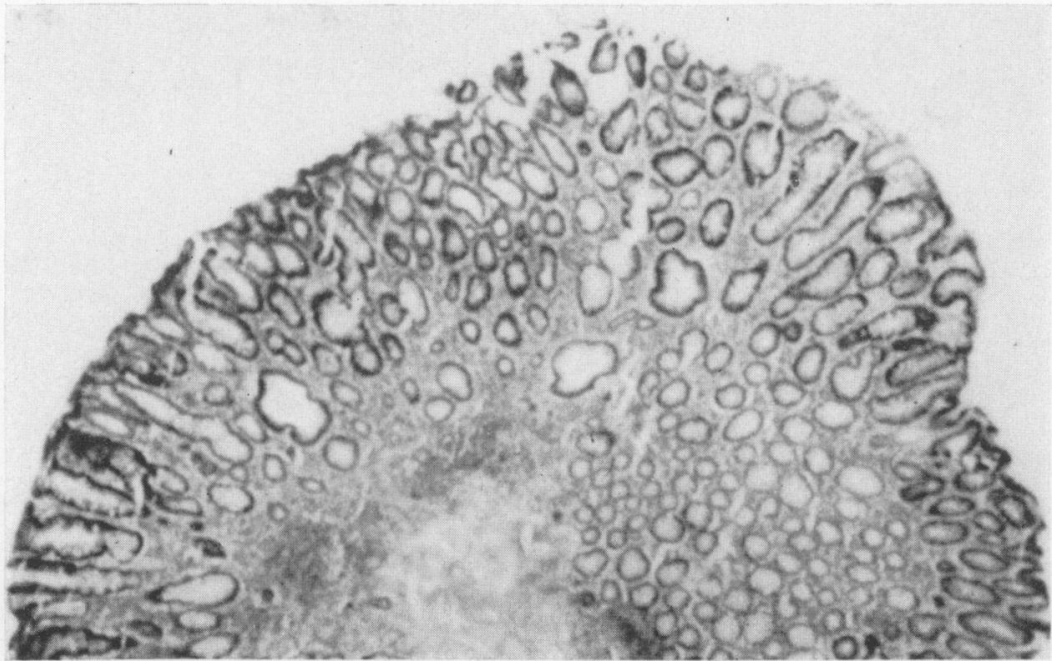

FIG. 1. (a) Histological section of the polyp showing the pedicle. (b) Same histological picture showing only the glandular structure of the polyp. 
formed by projecting ureters was an important factor. Sammo and Traverso (1967) studied histological and histochemical changes in bowel mucosa of patients and noted a period of proliferation affecting the glandular epithelium characterized by marked cellular hyperplasia and over-production of mucus. It may be the urine bathing the colon which potentiates the development of neoplasia several years later, but it is not clear why some patients develop benign lesions and others carcinoma. Colonic polyps are not uncommon, but the fortuitous occurrence of two polypi precisely at the ureteric orifice is improbable. The commonest presenting symptoms appear to be rectal bleeding and ureteral obstruction. In the present case, rectal bleeding was the presenting feature. The subsequent ureteric obstruction was iatrogenic.

The incidence of neoplasia at the anastomotic site appears to be confined to the colon rather than the ileum. The possibility of neoplasia should be kept in mind when this type of operation is performed, as with improved techniques and better management these patients have much longer life expectancy.

Long-term follow-up is necessary in ureterocolonic anastomosis for urological reasons, but it is also necessary to bear neoplasia in mind when examining the anastomotic site.

\section{References}

ALDIs, A.S. (1961) Carcinoma of colon following trans- plantation of ureters and at the site of transplantation. Proceedings of the Royal Society of Medicine, 54, 159.

BRICKer, E.M. (1950) Symposium on clinical surgery, bladder substitution after pelvic evisceration. Surgical Clinics of North America, 30, 1511.

Ellis, F.G. (1962) Adenocarcinoma complicating ureterosigmoidostomy. Proceedings of the Royal Society of Medicine, 55, 100.

FERGuSON, L.K. (1966) In: Discussion, Urdaneta, J.A., Duffel, D., August, J.B., Late development of carcinoma of the colon following uretero-sigmoidostomy. Annals of Surgery, 64, 503.

GillmaN, J.C. (1964) Adenomatous polyp of bowel following uretero-colonic anastomosis. British Journal of Urology, 36, 264.

HAMMER, E.M. (1929) Journal d'urologie médicale et chirurgicale, 28, 260. [Quoted by Gillman, J.C., 1964.]

HANEY, M.J. \& McGarity, W.C. (1971) Ureterosigmoidostomy and neoplasma of the colon. Archives of Surgery, 103, 69.

KILle, J.N. \& Glick, S. (1967) Neoplasia complicating uretero-sigmoidostomy. British Medical Journal, 4, 783.

MAcGregor, A.M.C. (1968) Mucus-secreting adenomatous polyp at the site of uretero-sigmoidostomy. British Journal of Surgery, 55, 591.

Markowitz, A.M. \& Koontz, P. (1966) The development of colonic polyps at the site of ureteral implantation. Surgery, 60, 761.

Rivard, J.Y., Bedard, A. \& Dionne, L. (1975) Colonic neoplasma following uretero-sigmoidostomy. Journal of Urology, 113, 781.

Sammo, G. \& Traverso, G.B. (1967) Modificazione esthochimiche della mucosa rettale in sogetti operati di uretero sigmoidotamia. Pathologica, 59, 447. 